\title{
К ВОПРОСУ РАЗВИТИЯ ГЛОБАЛЬНЫХ (ТРАНСНАЦИОНАЛЬНЫХ) УНИВЕРСИТЕТОВ В ПРОЕКЦИИ ПЕРСПЕКТИВ И РИСКОВ ВЫСШЕГО ОБРАЗОВАНИЯ В РОССИЙСКОЙ ФЕДЕРАЦИИ
}

\author{
(c) 2021 Долгова Елена Геннадьевна \\ кандидат филологических наук, доцент, кафедра иностранных языков № 3 \\ Российский экономический университет им. Г. В. Плеханова, Россия, Москва \\ Email: artzishevich@inbox.ru \\ (c) 2021 Казимирова Ирина Сергеевна \\ кандидат филологических наук, доцент, кафедра иностранных языков № 3 \\ Российский экономический университет им. Г. В. Плеханова, Россия, Москва \\ E-mail: irinacasimirova@yandex.ru \\ (C) 2021 Кузнецова Юлия Андреевна \\ кандидат экономических наук, доцент, кафедра иностранных языков № 3 \\ Российский экономический университет им. Г. В. Плеханова, Россия, Москва \\ E-mail: yulia_success@mail.ru

\section{(c) 2021 Николаева Елена Анатольевна} \\ кандидат социологических наук, доцент, кафедра иностранных языков № 3 \\ Российский экономический университет им. Г. В.Плеханова, Россия, Москва \\ E-mail:yoltash82@mail.ru
}

В статье авторов освещен вопрос развития глобальных (транснациональных) университетов в проекции перспектив и рисков в Российской Федерации. Объектом исследования выступили глобальные (транснациональные) университеты Российской Федерации, а предметом - их перспективы и риски в динамическом аспекте за десятилетний период. Теоретическое и методологическое значение исследования заключены в развитии методической и методологической базы глобального информационного проектирования. Также теоретическая значимость исследования определяется модернизацией некоторых элементов теории глобального риск-менеджмента. Практическое и прикладное значение исследования заключены в выявлении и анализе значимой тенденции развития глобальных (транснациональных) университетов с учетом факторов риска на уровне Российской Федерации.

Ключевые слова: Вопрос, развитие, глобализация, интернационализация, университет, проекция, перспектива, риск, Российская Федерация.

Глобализация - является одной из современных инициатив, тривиально пронизывающих практически все без исключения плоскости человеческой деятельности, включая такие важные ее аспекты, как экономика, информатизация и образование $[1,4]$.

Данный тезис, как в мировом парадигма, так и в реалиях Российской Федерации неоднократно анализировался (как в комплексе, там и в аспекте отдельных элементов) и подтвержден исследованиями целого ряда передовых консалтинговых институтов и рейтинговых агентств, включая ТерраЛинк, СберРешения и Эксперт РА $[5,6,7]$.

Для охарактеризования указанного выше те- зиса в рамках последнего аспекта рассмотрим динамику интегрального индекса глобализации (транснационализации) системы образования в мировом масштабе за последние 10 лет (рис. 1). Обозначенный индекс измеряется в единицах (безразмерные величины) и изменяется в пределах от 0 единиц (минимально возможное значение) до 100 единиц (максимально возможное значение).

Данные рисунка 1 за анализируемый период времени отчетливо свидетельствуют о наличии восходящей тенденции развития системы образования в мировом масштабе с явными пиками роста в 2015 и 2017 годах. При этом основные пики снижения индекса глобализации объекта 


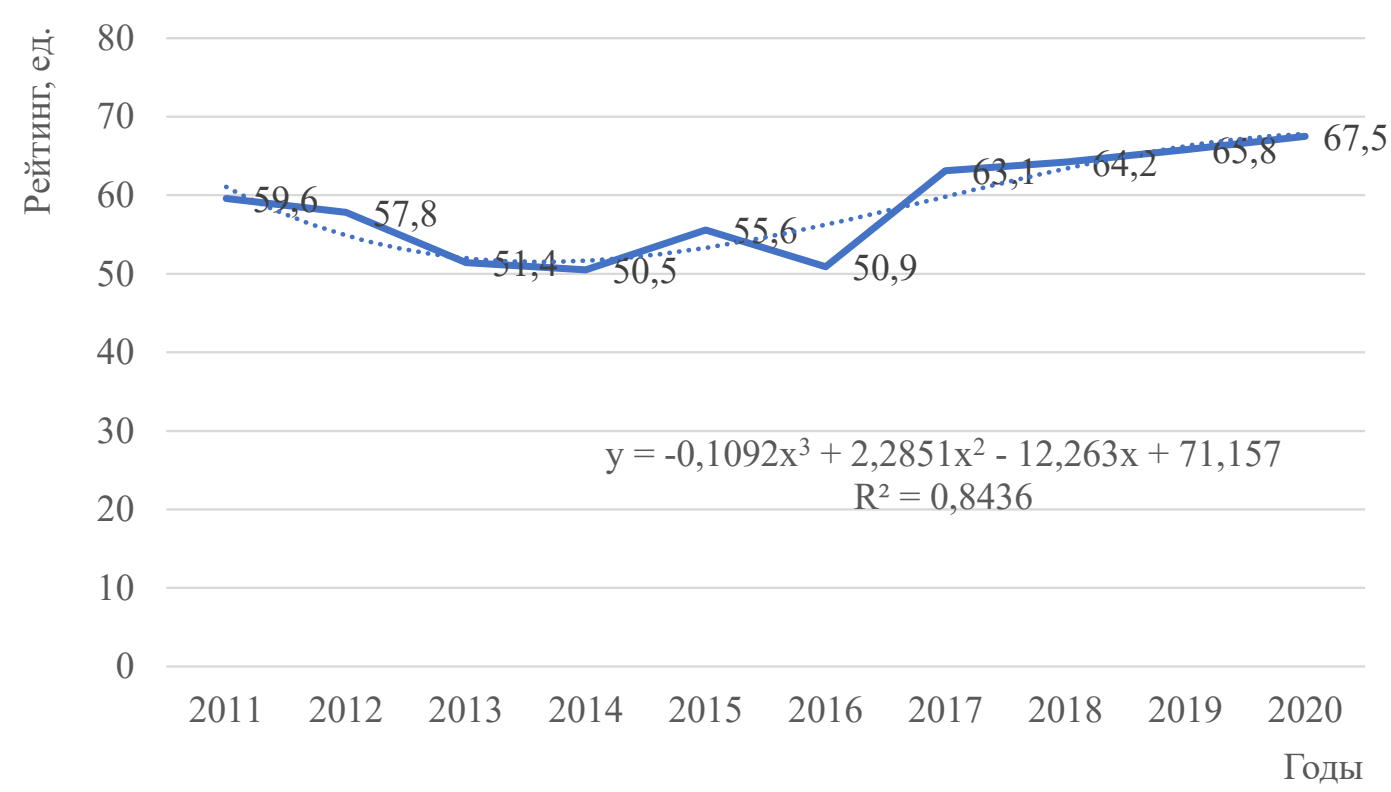

Puc. 1. Динамика интегрального индекса глобализации системы образования в мировом масштабе за 2011-2020 годы

явно имели место в 2014 и 2016 годах. Некоторые второстепенные пики снижения можно отметить в 2012 и 2013 годах. Совокупное изменение исследуемого индекса за 2011-2020 годы составило $+7,9$ единицы или $+1,13$ раза $(+113,25$ процента).

Для сравнения ниже приведены данные по динамике интегрального индекса глобализации системы образования в Российской Федерации (в части системы высшего образования [3, с.105]) за 2011-2020 годы (рис. 2).

Из рисунка 2 можно увидеть, что в целом, несмотря на наличие нескольких явных разно- направленных пиков роста (явные восходящие пики имели место в 2016 и 2020 годах, второстепенные в 2014, 2018 и 2019 годах) и снижения (явные нисходящие пики имели место в 2015 и 2017 годах, второстепенные в 2012 и 2013 годах), динамика анализируемого индекса носит восходящий характер. Совокупное изменение интегрального индекса глобализации системы образования в Российской Федерации (в части системы высшего образования) за 2011-2020 годы составило $+9,03$ единицы или $+1,19$ раза (+118,74 процента).

На фоне вышеописанной динамической

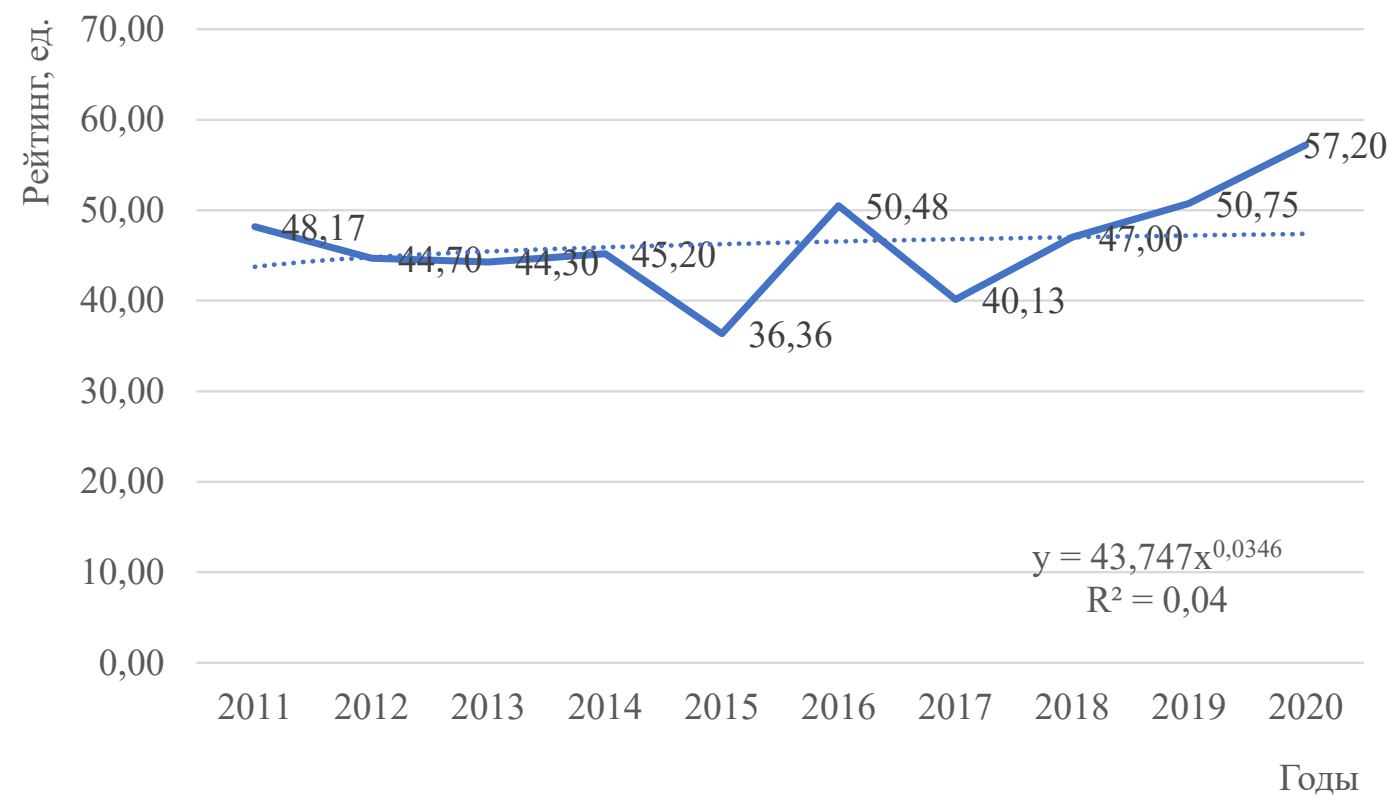

Puc. 2. Динамика интегрального индекса глобализации системы образования в Российской Федерации (в части системы высшего образования) за 2011-2020 годы 
картины высшего образования в Российской Федерации был проведен анализ глобальных (транснациональных) университетов. Результаты данного анализа за 2011-2020 годы по некоторым ключевым показателям (индекс текущего состояния, индекс среднесрочной перспективы, индекс долгосрочной перспективы, индекс рисков [2, с.71]) отражены в таблице 1.

На основе данных, приведенных в таблицы 1 , можно сделать следующие выводы:

- индекс текущего состояния: за анализируемый период времени увеличился с 19,36 единиц до 27,92 единицы (абсолютное изменение значений данного показателя составило $+8,56$ единицы, а относительное $+1,44$ раза). Среднее значение индекса текущего состояния за 20112020 годы составило 24,08 единицы, что в целом может характеризовать развитие глобальных университетов в Российской Федерации в текущем положении как удовлетворительное;

- индекс среднесрочной перспективы: за анализируемый период времени увеличился с 36,85 единиц до 48,57 единицы (абсолютное изменение значений данного показателя составило $+11,72$ единиц, а относительное $+1,32$ раза). Среднее значение индекса среднесрочной перспективы за 2011-2020 годы составило 42,95 единицы, что в целом может характеризовать развитие глобальных университетов в Российской Федерации в среднесрочном периоде времени как достаточное;
- индекс долгосрочной перспективы: за анализируемый период времени увеличился с 58,56 единицы до 73,25 единицы (абсолютное изменение значений данного показателя составило $+14,69$ единицы, а относительное $+1,25$ раза). Среднее значение индекса долгосрочной перспективы за 2011-2020 годы составило 64,39 единицы, что в целом может характеризовать развитие глобальных университетов в Российской Федерации в среднесрочном периоде времени как устойчивое;

- индекс рисков: за анализируемый период времени уменьшился с 49,35 единиц до 30,98 единиц (абсолютное изменение значений данного показателя составило $-18,37$ единиц, а относительное 0,63 раза). Среднее значение индекса рисков за 2011-2020 годы составило 43,10 единицы, что в целом может характеризовать развитие глобальных университетов в Российской Федерации как умеренно рисковое.

Таким образом, можно сделать вывод, что вопрос развития глобальных (транснациональных) университетов в Российской Федерации является достаточно актуальным и осуществляется в значительном соответствии с поляризацией интегрального индекса глобализации системы высшего образования в Российской Федерации за 2011-2020 годы в целом.

Анализ исследуемого процесса в проекциях перспектив и рисков позволил заключить следующее:

Таблица 1. Результаты анализа развития глобальных (транснациональных) университетов в Российской Федерации за 2011-2020 годы по некоторым ключевым показателям, уровень, ед.

\begin{tabular}{|c|c|c|c|c|}
\hline \multirow{2}{*}{ Годы } & \multicolumn{4}{|c|}{ Показатели } \\
\cline { 2 - 5 } & $\begin{array}{c}\text { Индекс текущего } \\
\text { состояния }\end{array}$ & $\begin{array}{c}\text { Индекс среднесроч- } \\
\text { ной перспективы }\end{array}$ & $\begin{array}{c}\text { Индекс долгосроч- } \\
\text { ной перспективы }\end{array}$ & $\begin{array}{c}\text { Индекс } \\
\text { рисков }\end{array}$ \\
\hline 2011 & 19,36 & 36,85 & 58,56 & 49,35 \\
\hline 2012 & 23,58 & 37,28 & 63,12 & 57,18 \\
\hline 2013 & 24,29 & 35,25 & 65,18 & 37,38 \\
\hline 2014 & 25,21 & 45,88 & 62,64 & 54,55 \\
\hline 2015 & 19,81 & 50,16 & 58,37 & 42,41 \\
\hline 2016 & 24,24 & 43,76 & 63,62 & 50,36 \\
\hline 2017 & 25,18 & 42,15 & 64,18 & 36,35 \\
\hline 2018 & 24,35 & 44,11 & 65,96 & 32,11 \\
\hline 2019 & 26,86 & 45,46 & 68,98 & 30,98 \\
\hline 2020 & 27,92 & 48,57 & 73,25 & 43,10 \\
\hline $\begin{array}{c}\text { Абсолютное } \\
\text { изменение }\end{array}$ & 24,08 & 42,95 & 64,39 & $-18,37$ \\
\hline Относительное & 8,56 & 11,72 & 14,69 & 0,63 \\
\hline
\end{tabular}


- текущие перспективы развития глобальных (транснациональных) университетов в Российской Федерации можно оценить как удовлетворительные (их среднее значение за 2011-2020 годы не выходило за пределы 25 единиц);

- среднесрочные перспективы развития глобальных (транснациональных) университетов в Российской Федерации можно оценить как достаточные (их среднее значение за 2011-2020 годы не выходило за пределы 45 единиц);

- долгосрочные перспективы развития глобальных (транснациональных) университетов в Российской Федерации можно оценить как устойчивые (их среднее значение за 2011-2020 годы превысило 60 единичный рубеж);
- относительное изменение трех показателей, характеризующих перспективы развития глобальных (транснациональных) университетов в Российской Федерации, носит нисходящий характер (от 1,44 раза для текущего состояния до 1,25 раза для долгосрочного состояния), что, в целом, свидетельствует о нормальном распределении показателей во времени;

- риски, присущие развитию глобальных (транснациональных) университетов в Российской Федерации со временем нивелируются (вероятнее всего, ввиду активных действий на федеральном уровне), что стабилизирует анализируемый процесс и в будущем приведет его к среднемировому состоянию.

\section{Библиографический список}

1. Муравьева А. А., Олейникова О.Н. и др. Основные векторы развития высшего образования: международная перспектива / А. А. Муравьева, О.Н. Олейникова, А. О. Викторова // Вестник Нижегородского университета им. Н.И. Лобачевского. Серия: социальные науки - Нижний Новгород: Изд-во: «Национальный исследовательский Нижегородский государственный университет им. Н. И. Лобачевского», 2019. - № 4. - С. 311-320.

2. Неборский Е. В. Сегодняшнее завтра: глобальные риски как фактор трансформации высшего образования / Е.В.Неборский / Отечественная и зарубежная педагогика - М: Изд-во: «Институт стратегии развития образования РАО», 2020.- № 4.- С. 62-74.

3. Сураева М.О. Проблемы оценки качества образования в высшей школе в условиях перехода на дистанционное обучение в Российской Федерации / М. О. Сураева / Экономические науки - Москва: Изд-во: «ООО «24 Принт», 2019. - № 4.- С. 104-108.

4. Танцура T.A. Особенности процесса интеграции современных университетов в мировое пространство высшего образования / Т. А. Танцура / Самоуправление - М: Изд-во: «Вольное экономическое общество Москвы», 2020.- № 1.- С. 399-401.

5. Компания «СберРешения» [Электронный ресурс]: аналитические материалы - Официальный сайт компании «СберРешения», 2021.- Режим доступа: https://sber-solutions.ru/about

6. Компания «ТерраЛинк» [Электронный ресурс]: аналитические материалы - Официальный сайт компании «ТерраЛинк», 2021.- Режим доступа: https://www.terralink.ru/company/

7. Компания «Эксперт РА» [Электронный ресурс]: аналитические материалы - Официальный сайт компании «Эксперт РА», 2021.- Режим доступа: https://raexpert.ru/ 